\title{
Downregulation of MicroRNA-19b Contributes to Angiotensin II-Induced Overexpression of Connective Tissue Growth Factor in Cardiomyocytes
}

\author{
Song Gao ${ }^{a}$ Tie-wen Liu ${ }^{b}$ Zhe Wang ${ }^{c}$ Zhen-yu Jiao ${ }^{c}$ Jun Cai ${ }^{c}$ Hong-jie Chic \\ Xin-chun Yang ${ }^{c}$ \\ ${ }^{a}$ Texas Heart Institute, Houston, Tex., and ${ }^{b}$ Department of Molecular Pharmacology, Diabetes Research Center, \\ Institute of Aging, Albert Einstein College of Medicine, New York, N.Y., USA; ' Department of Cardiology, \\ Chaoyang Hospital, Capital Medical University, Beijing, China
}

\section{Key Words}

Angiotensin II · Connective tissue growth factor .

MicroRNA · Cardiomyocytes

\begin{abstract}
Objectives: The present study was designed to decipher the molecular mechanisms underlying angiotensin (Ang) II-induced overexpression of connective tissue growth factor (CTGF) in cultured cardiomyocytes. Methods: Cardiomyocytes isolated from 1- to 3-day-old neonatal rats were cultured and treated with $100 \mathrm{nM}$ Ang II with or without pretreatment with $10 \mathrm{~nm}$ telmisartan, an Ang II type 1 receptor antagonist. The role of microRNA (miR)-19b in the regulation of Ang II-induced CTGF expression was evaluated in cultured cardiomyocytes with quantitative real-time reverse transcription polymerase chain reaction and Western blot analysis. Results: We provide several lines of evidence to show that miR-19b contributes to the Ang II-induced overexpression of CTGF in cultured cardiomyocytes. Firstly, administration of Ang II decreased the level of miR-19b dramatically ( $p<0.05$ vs. control), which was abolished by telmisartan. Secondly, Ang II increased the level of CTGF significantly $(p<$ 0.05 vs. control), which was also prevented by pretreatment with telmisartan. Thirdly, overexpression of miR-19b decreased CTGF levels ( $p<0.05$ vs. control). Finally, transfection of miR-19b into cardiomyocytes prevented the upregu-
\end{abstract}

\section{KARGER}

(c) 2013 S. Karger AG, Basel

0008-6312/13/1272-0114\$38.00/0

E-Mail karger@karger.com

www.karger.com/crd lation of CTGF induced by Ang II. Conclusion: Downregulation of miR-19b contributes to Ang Il-induced overexpression of CTGF in cultured cardiomyocytes. @ $2013 \mathrm{~S}$. Karger AG, Basel

\section{Introduction}

Fibrosis is one of the most important characteristics of cardiac remodeling during heart failure $[1,2]$. The accumulation of extracellular matrix (ECM) proteins within the myocardium is the major feature of cardiac fibrosis. Connective tissue growth factor (CTGF) has been identified as a powerful inducer of ECM and plays an important role in ECM responses and cardiac fibrosis during heart failure [3-6]. It belongs to the highly conserved CCN family of growth factors (Cyr 61, CTGF and NOV) [7, 8], and the most prominent feature of CTGF is its overexpression in fibrosis of various organs including lung, kidney, skin and heart [9]. Several lines of evidence indicate that CTGF is involved in angiotensin (Ang) II-induced myocardial fibrosis during heart failure $[10,11]$. It has been demonstrated that cardiomyocytes produce CTGF in response to Ang II $[12,13]$. However, the mechanism

H.C. and X.Y. contributed equally to this work. 
of Ang II-induced CTGF expression in cardiomyocytes is still unclear.

MicroRNAs (miRs) are small, approximately 22-nucleotide noncoding RNAs that inhibit transcription or translation by interacting with the $3^{\prime}$ untranslated region ( $3^{\prime}$-UTR) of target mRNAs [14]. Discovery of miR has revolutionized our understanding of the mechanisms that regulate gene expression, and we are compelled to revise our understanding of the mechanisms regulating normal and pathological cellular functions. Ikeda et al. [15] measured the expression of $428 \mathrm{miRs}$ in samples from patients with dilated cardiomyopathy and heart failure and found that miR-19 was the most strongly downregulated miR family. miR-19b was further demonstrated to be involved in age-related heart failure by upregulation of CTGF [16]. This, together with the important role of Ang II in fibrosis of heart failure, has led us to hypothesize that miR-19b may be involved in Ang II-induced overexpression of CTGF in cardiomyocytes. Therefore, we investigated whether miR-19b participates in Ang II-induced overexpression of CTGF in cultured cardiomyocytes to elucidate the possible mechanism of fibrosis during heart failure.

\section{Materials and Methods}

\section{Study Approval}

All experimental procedures and protocols used in this study were reviewed and approved by the Institutional Animal Care and Use Committee of The Capital Medical University, Beijing, China.

\section{Isolation and Culture of Neonatal Rat Cardiomyocytes}

Primary culture of neonatal cardiomyocytes was prepared as described previously [17]. One- to 3-day-old rats were sacrificed, and the hearts were placed in ice-cold Hanks balanced salt solution. The lower one third of the heart was separated from the rest and cut into smaller pieces with surgical scissors. The pieces were incubated with $5 \mathrm{ml}$ of digestion buffer containing $75 \mathrm{U} / \mathrm{ml}$ collagenase II (Worthington) and gently stirred at $37^{\circ} \mathrm{C}$ for $20 \mathrm{~min}$. The digest was collected, and the digestion process was repeated 6 times. The cells were then centrifuged at $283 \mathrm{~g}$ for $5 \mathrm{~min}$ and resuspended in serum-containing medium ( $10 \%$ fetal bovine serum, $1 \%$ penicillin-streptomycin, 1:1 DMEM-F-12, Invitrogen). The cells were preplated in dishes (BD Falcon) for $1 \mathrm{~h}$ to attach noncardiac cells. The nonattached cells were plated to culture dishes precoated with gelatin in DMEM-F-12 medium. Cardiomyocytes were allowed to attach to the plate wall and were then deprived of serum for $48 \mathrm{~h}$ in DMEM-F-12 medium containing $0.1 \%$ bovine serum albumin.

Transfection of Precursor of miR-19b in Neonatal Rat

Cardiomyocytes and Ang II Stimulation

Synthetic miR-19b precursor for mature miR-19b (Catalog No. AM17100; ID: PM10629) and pre-miR ${ }^{\mathrm{TM}}$-Negative Control (Cata- $\log$ No. AM17110) were purchased from Ambion. Pre-miR miR precursors are small, double-stranded RNAs that mimic endogenous precursor miRs. It was designed to optimize selection of the correct strand for uptake and activation by the RNA-induced silencing complex. After $48 \mathrm{~h}$ of starvation in serum-free medium, neonatal rat cardiomyocytes $\left(4 \times 10^{4}\right.$ per well $)$ were treated with miR-19b precursor for $48 \mathrm{~h}$ using siPORT NeoFX Transfection Agent (Ambion) according to the manufacturer's instructions.

A subset of cells was treated with $100 \mathrm{nM}$ Ang II (Sigma) for $48 \mathrm{~h}$ with or without pretreatment with $10 \mu \mathrm{M}$ telmisartan (Abcam) 30 min before the administration of Ang II.

\section{RNA Extraction from Cardiomyocytes and Quantitative}

\section{Real-Time Polymerase Chain Reaction}

Total RNA was extracted from cells using TRIzol Reagent (Invitrogen) following the manufacturer's instructions. For miR-19b, quantitative real-time (qRT)-PCR was performed using mirVana qRT-PCR primer sets and TaqMan miRNA assay kits (Ambion) according to the manufacturer's protocols. U6 snRNA was used as an internal control of variations. qRT-PCR was used to assess the mRNA expression of CTGF and glyceraldehyde 3-phosphate dehydrogenase. The PCR products were visualized and quantified by $1 \%$ agarose gel electrophoresis analysis.

\section{Protein Extraction and Western Blotting Analysis}

Proteins were extracted from cells according to previously established methods [18]. Equal amounts of denatured proteins $(30 \mu \mathrm{g})$ were electrophoresed on precasted $10 \%$ Tris-glycine gel (Bio-Rad) for $2 \mathrm{~h}$ at $200 \mathrm{~V}$ and then transferred to Immobilon-P membranes (Millipore). The membranes were then blocked with $5 \%$ bovine serum albumin at room temperature for $1 \mathrm{~h}$ and then hybridized with CTGF (1:500 dilution; Santa Cruz, Calif., USA) and glyceraldehyde-3-phosphate dehydrogenase (1:5,000 dilution; Sigma) antibodies at $4^{\circ} \mathrm{C}$ overnight. After 3 consecutive washings of 10 min using PBS-Tween 20 buffer, the membranes were further incubated with secondary antibody at room temperature for $1 \mathrm{~h}$. The membranes were washed 3 times with PBS-Tween 20 for $10 \mathrm{~min}$ each, and a hybridization signal was visualized using an electrochemiluminescence kit (Thermo). The intensity of the bands was quantified using ImageJ software.

\section{Bioinformatics and miR Target Analysis}

Analysis of predicted targets of miR-19b was based on the TargetScan prediction program (http://www.targetscan.org).

\section{Data Analysis}

All results were expressed as means \pm SD. Differences were evaluated using a t test or analysis of variance. Probability values less than 0.05 were considered significant. All experiments were performed 3 times or more.

\section{Results}

\section{Effect of Ang II on Expression of miR-19b in}

Cardiomyocytes

To determine whether Ang II can regulate the expression of miR-19b and whether telmisartan, an antagonist 
of Ang II type 1 receptor $\left(\mathrm{AT}_{1} \mathrm{R}\right)$, can abolish the effect, we characterized the effect of Ang II on cultured cardiomyocytes with qRT-PCR. The results showed that exposure to $100 \mathrm{nM}$ Ang II for $48 \mathrm{~h}$ downregulated miR-19b in cultured cardiomyocytes significantly compared with control. Pretreatment of the cardiomyocytes with $10 \mu \mathrm{M}$ telmisartan partially prevented the Ang II-induced downregulation of miR-19b (fig. 1).

\section{Effect of Ang II on CTGF Gene and Protein Expression} in the Cultured Cardiomyocytes

To determine the effect of Ang II on CTGF expression in cultured cardiomyocytes, we detected the CTGF mRNA and protein expression levels in cultured cells. As shown in figure $2 \mathrm{a}$ and $\mathrm{b}$, CTGF mRNA expression was significantly increased after Ang II stimulation ( $\mathrm{p}<0.05$ vs. control group). When compared with the Ang II-treated group, the induction of CTGF gene expression was prevented by preincubation with telmisartan $(\mathrm{p}<0.05)$. The result of Western blot showed that Ang II regulated the expression of CTGF at protein level, and preincubation with telmisartan prevented the effect of Ang II on CTGF expression (fig. 2c, d). These results suggest a mechanism that mediates the regulation of expression of CTGF genes by Ang II via an $\mathrm{AT}_{1} \mathrm{R}$-dependent pathway.

\section{CTGF Production Is Regulated by miR-19b in \\ Cultured Cardiomyocytes}

To identify and analyze downstream targets of miR$19 \mathrm{~b}$ in cardiomyocytes, we used TargetScan to predict downstream targets of miR-19b. The $3^{\prime}$-UTR of rat CTGF (NM_010217) mRNA was predicted to be a putative target for miR-19b (fig. 3a). With transfection of miR-19b precursor into cultured cardiomyocytes, the miR-19b expression was dramatically induced compared with the negative control group of pseudorandom sequences (fig. 3b). To explore the possible involvement of miR-19b in the regulation of expression of CTGF, we performed functional studies to determine the role of miR-19b in the regulation of CTGF production in cardiomyocytes. As shown in figure $3 \mathrm{c}$, transfection of miR-19b precursor into the cultured cardiomyocytes dramatically reduced the mRNA level of CTGF. The analysis of agarose gel electrophoresis confirmed the decrease in CTGF expression induced by miR-19b (fig. 3d).

Evidence for Decreased miR-19b Level Underlying Ang II-Induced Upregulated CTGF Expression

To explore the possible involvement of miR-19b in the regulation of expression of CTGF in cardiomyocytes, we

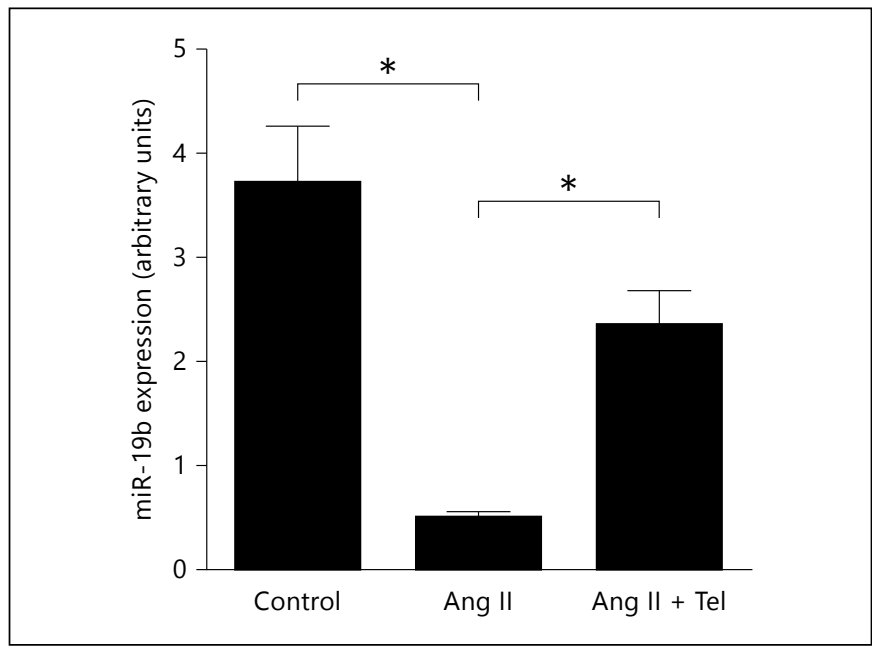

Fig. 1. Ang II regulates miR-19b expression in cultured cardiomyocytes. Data represent means \pm SD. All experiments were performed 3 times. ${ }^{*} \mathrm{p}<0.05$. Tel $=$ Telmisartan.

transfected miR-19b precursor into Ang II-stimulated cardiomyocytes. The results of qRT-PCR and Western blot showed that the upregulation effect of Ang II on CTGF expression was antagonized at both the mRNA (fig. 4a) and protein level (fig. 4b, c) by transfection of miR-19b precursor.

\section{Discussion}

In this study, we demonstrated that Ang II upregulates CTGF expression and downregulates miR-19b expression in cultured cardiomyocytes. All these effects of Ang II can be abolished by telmisartan, which is an $\mathrm{AT}_{1} \mathrm{R}$ antagonist. We further verified that overexpression of miR$19 \mathrm{~b}$ results in posttranscriptional repression of CTGF in cardiomyocytes. Transfection of miR-19b prevented the upregulation of CTGF induced by Ang II in cardiomyocytes. The present study therefore revealed downregulation of miR-19b as a molecular mechanism by which Ang II promotes cardiac fibrosis.

As mentioned above, cardiac fibrosis is characterized by the accumulation of ECM proteins, which contributes to cardiac stiffness and can eventually impair cardiac function and lead to the development of heart failure [19]. The exact mechanisms responsible for myocardial fibrosis remain to be clearly defined. Ang II has been suggested to be a potent profibrotic molecule [19]. Increased serum levels of Ang II are seen in patients with heart failure. With inhibition of the renin-angiotensin system, clinical 
Fig. 2. Ang II regulates CTGF expression in cultured cardiomyocytes. a qRT-PCR analysis of the mRNA expression of CTGF. b The PCR products were visualized and quantified by $1 \%$ agarose gel electrophoresis analysis. c Western blot analysis of protein expression of CTGF. $\mathbf{d}$ ImageJ analysis of the intensity of protein expression of CTGF by Western blot analysis. Data represent means $\pm \mathrm{SD}$. All experiments were performed 3 times. ${ }^{*} \mathrm{p}<0.05$. Tel $=$ Telmisartan; GAPDH = glyceraldehyde-3-phosphate dehydrogenase.

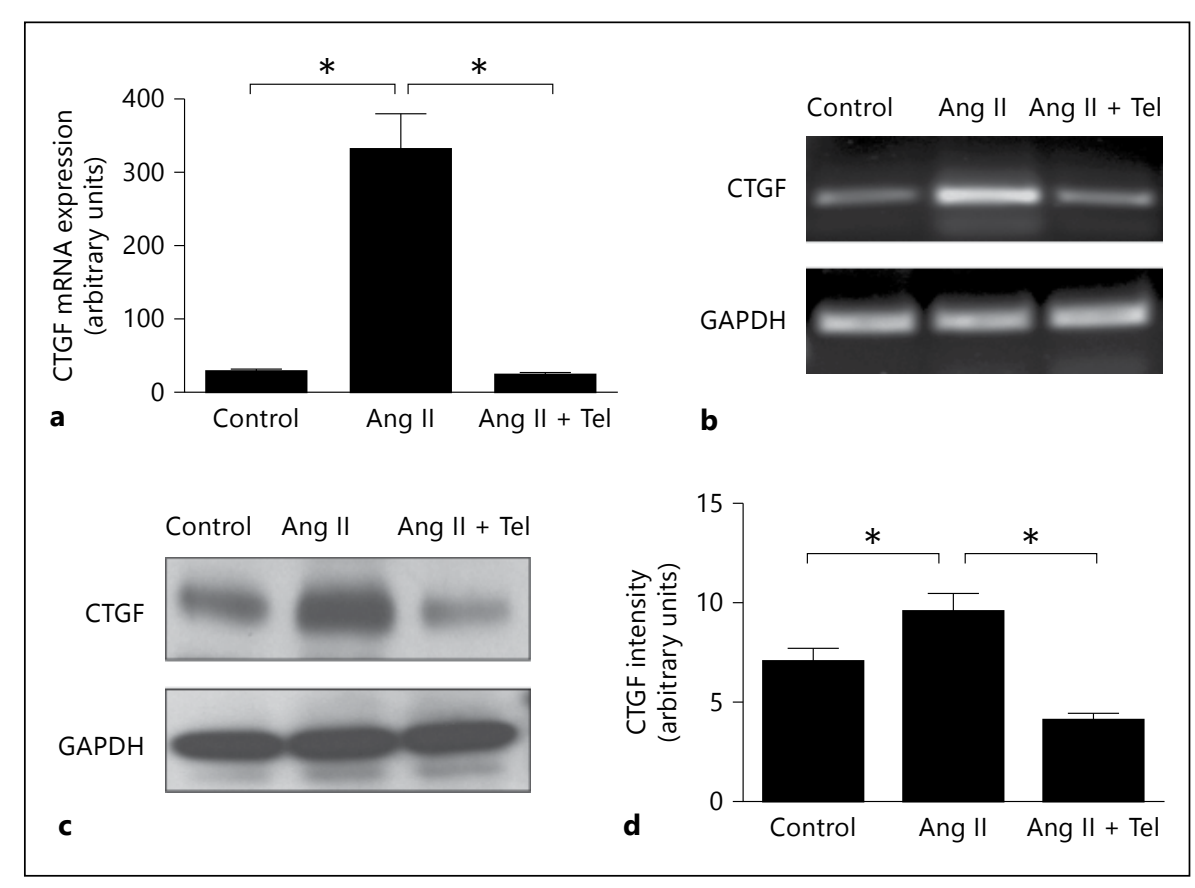

trials demonstrated significant benefit in the prevention of cardiac remodeling and myocardial fibrosis $[19,20]$. Moreover, Ang II given exogenously to rodents has been shown to result in cellular changes within the myocardium, hypertrophy and eventual fibrosis, similar to that seen in humans [20-23]. Taken together, this evidence strongly supports a role for Ang II in the development of myocardial fibrosis. However, the exact mechanisms and the involved cells have yet to be fully characterized.

Using an Ang II infusion model of myocardial fibrosis, Sopel et al. [24] demonstrated that Ang II infusion resulted in rapid infiltration of fibroblast progenitor cells, termed fibrocytes. Fibrocytes are capable of producing both proinflammatory mediators and fibrogenic factors, such as CTGF, which is mainly synthesized and released by cardiac fibroblasts in the heart. The expression and regulation of CTGF in cardiac fibroblasts have been studied extensively [25]. Cardiomyocytes can also produce CTGF under the stimulation of transforming growth factor- $\beta$, endothelin and Ang II $[5,26]$, which would contribute to a paracrine control of cardiac fibroblast functions [27] and regulate the surrounding ECM environment $[4,5,28]$. Consistent with these findings, our results demonstrated that Ang II can upregulate the expression of CTGF at both mRNA and protein levels. The results support the notion that the overexpression of CTGF in cardiomyocytes with stimulation by Ang II may contribute to cardiac fibrosis during heart failure.

Downregulation of MicroRNA-19b and Ang II-Induced CTGF Expression
The upregulation of Ang II-induced CTGF expression at the promoter level has been studied by $\mathrm{He}$ et al. [13]. They demonstrated that protein kinase $\mathrm{C}$ mediates Ang II-induced CTGF expression in cardiomyocytes and may contribute to the development of cardiac fibrosis in diabetic cardiomyopathy and heart failure. However, little is known about how CTGF transcripts are regulated at the posttranscriptional level, and regulation of CTGF expression by miRs has not yet been described clearly.

The action of miRs involves incorporation of the single-stranded miR into the RNA-induced silencing complex and subsequent binding of the $\mathrm{miR}$ to the $3^{\prime}$-UTR of its target mRNA through exact complementarity with its $5^{\prime}$-end 7-8 nucleotides and partial complementarity with the rest of the sequence [29-32]. In this way, miRs cause translational inhibition. miR-19b is a member of miR-17-92 cluster. This cluster encodes 6 miRs (miR17, miR-18a, miR-19a, miR-19b, miR-20a and miR92a-1) that are located within an 800-base pair region of human chromosome 13. Originally, the miR-17-92 cluster was linked to tumor genesis, and transcript of the cluster was found to be directly activated by the protooncogene c-Myc [33]. Lakner et al. [34] performed miR microarray analysis on quiescent and activated rat hepatic stellate cells and found that miR-19b showed the highest fold change of the cluster members. They further demonstrated that miR-19b regulated transforming growth factor- $\beta$ signaling in hepatic stellate cells, sug- 

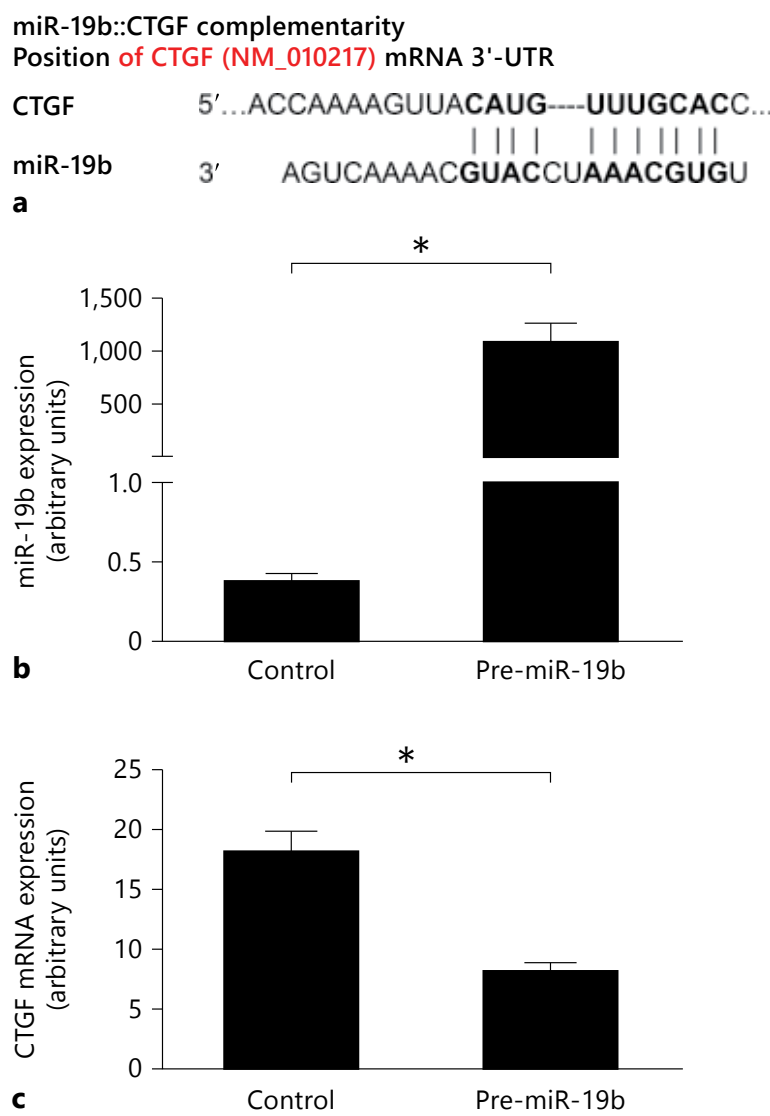

c

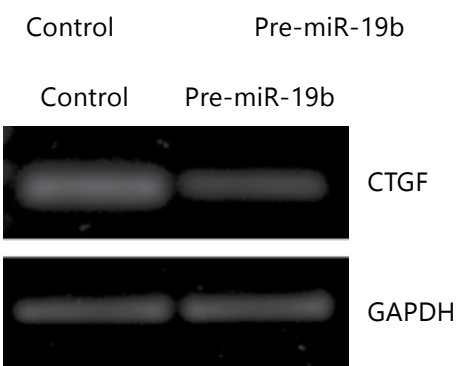

Fig. 3. Posttranscriptional repression of CTGF by miR-19b. a Complementarities between miR-19b and CTGF genes. miR-19b is presented in the form of mRNA from the $3^{\prime}$ end to the $5^{\prime}$ end. Mated bases are indicated by bold letters and lines connecting the letters. b $\mathrm{miR}-19 \mathrm{~b}$ precursor transfection increased miR-19b expression in cultured cardiomyocytes. c qRT-PCR analysis of CTGF mRNA expression. $\mathbf{d} \mathrm{qRT}$-PCR products were confirmed by $1 \%$ agarose gel electrophoresis. Data represent means \pm SD. All experiments were performed 3 times. ${ }^{*} \mathrm{p}<0.05$. Pre-miR-19b $=$ miR-19b precursor; $\mathrm{GAPDH}=$ glyceraldehyde-3-phosphate dehydrogenase.

gesting a potential role of $\mathrm{miR}-19 \mathrm{~b}$ in hepatic fibrosis [34]. Interestingly, cardiogenesis was severely hampered in mice deficient for miR-17-92, suggesting an important role for this cluster in cardiac development [35]. Van Almen et al. [16] demonstrated that miR-19 and

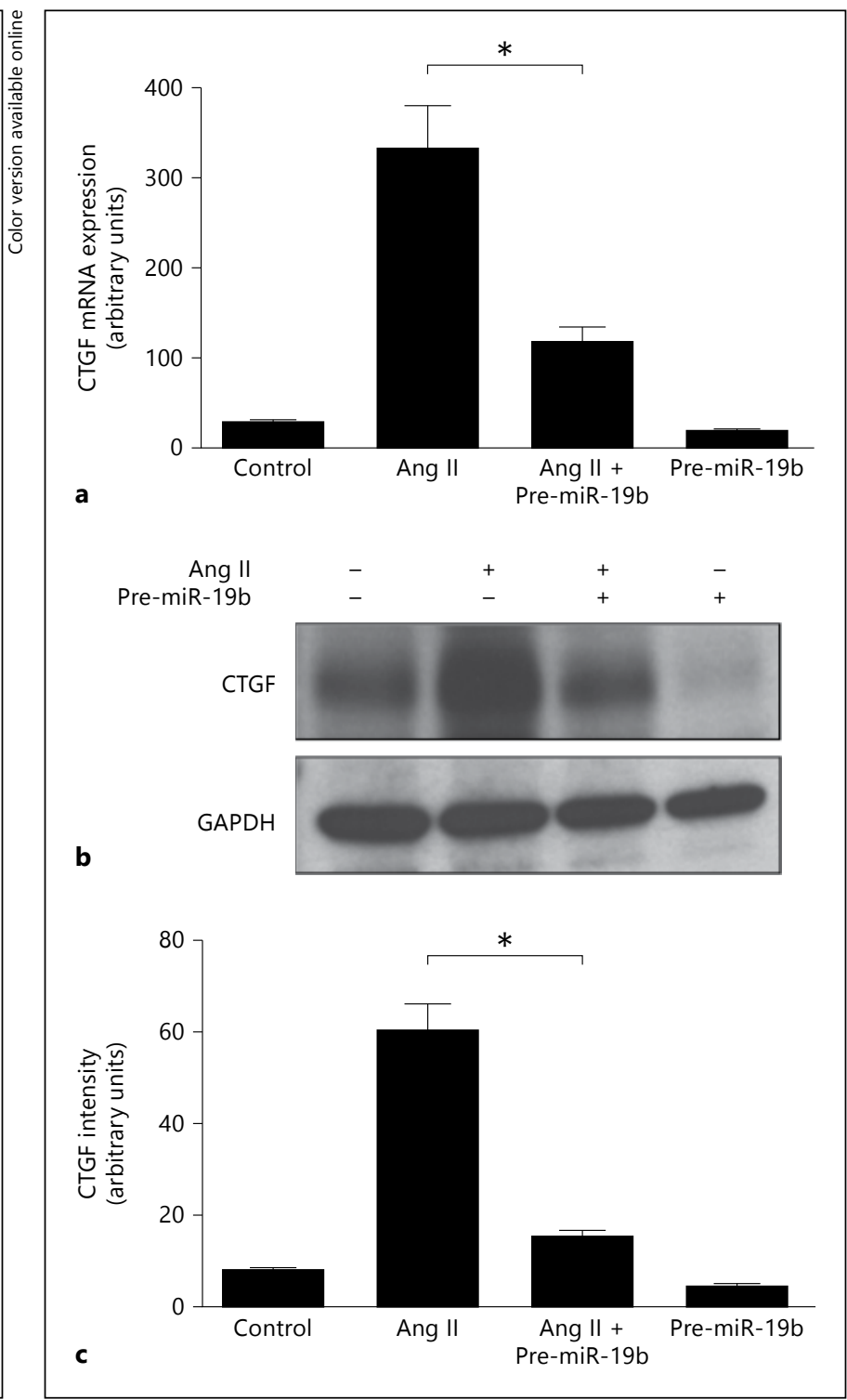

Fig. 4. Downregulation of miR-19b contributes to Ang II-induced expression of CTGF in cardiomyocytes. a qRT-PCR analysis of CTGF expression at the mRNA level. The error bars represent means $\pm \mathrm{SD}$ of experimental values performed in triplicate. b Western blot analysis of CTGF expression at the protein level. c Image J analysis of the intensity of protein expression of CTGF by Western blot analysis. Data represent means \pm SD. All experiments were performed 3 times. ${ }^{*} \mathrm{p}<0.05$. Pre-miR-19b $=$ miR$19 \mathrm{~b}$ precursor; GAPDH = glyceraldehyde-3-phosphate dehydrogenase.

miR-18 played an important role in cardiac fibrosis of age-related heart failure by regulation of CTGF expression. Our results support the notion that miR-19b regulates CTGF expression in cardiomyocytes. As shown in figure 3, the CTGF gene contains one putative binding 
site for miR-19b, which predicts that CTGF may be the target gene of miR-19b. The expression of CTGF was downregulated with the transfection of miR-19b into cardiomyocytes, which confirmed the regulative role of miR-19b in CTGF expression in cardiomyocytes. Moreover, for the first time, we tested the change in miR-19b in cardiomyocytes with stimulation by Ang II. As shown in figure 1, the expression of miR-19b in cardiomyocytes was downregulated extensively by Ang II, and coincubation with telmisartan abolished the effect and produced an overshoot. Further results showed that transfection of miR-19b prevented the Ang II-induced upregulation of CTGF expression at mRNA and protein levels, as shown in figure 4.

Probably the most striking finding of this study is that miR-19b is involved as a necessary mediator in Ang IIinduced CTGF expression. We showed that downregulation of miR-19b by Ang II is mediated by activation of $\mathrm{AT}_{1} \mathrm{R}$ because an antagonist of $\mathrm{AT}_{1} \mathrm{R}$ abrogates the action of Ang II on miR-19b. However, the present study does not answer the question of how $\mathrm{AT}_{1} \mathrm{R}$ activation leads to miR-19b downregulation. Further studies are needed to clarify the role of $\mathrm{AT}_{1} \mathrm{R}$ in miR-19b regulation. During the study, we found that the downregulation of CTGF expression by coincubation with telmisartan and Ang II is more pronounced than the upregulation of miR-19b expression. Telmisartan is not expected to activate signal- ling pathways but to interfere with Ang II-activated pathways. The exact mechanism of this result remains to be clarified. We are currently performing further investigations on this issue, and we hope that new data concerning regulation of CTGF expression by telmisartan will become available in the near future.

On the basis of our results, it appears reasonable to propose that Ang II exposure activates $\mathrm{AT}_{1} \mathrm{R}$ in cardiomyocytes, which then results in a downregulation of miR$19 \mathrm{~b}$ expression via some unknown mechanisms. Decreased miR-19b levels cause an upregulation of CTGF proteins due to a removal of posttranscriptional inhibition by miR. Increased CTGF results in ECM production and fibrosis generation. The clarification of miR-19b-regulatory effects on cardiomyocytes may open up a new strategy for controlling the development of cardiac fibrosis in heart failure.

\section{Acknowledgements}

This work was supported by the National Nature Science Foundation of China (81100168).

\section{Conflict of Interest}

The authors declare no potential conflicts of interest.

\section{References}

$>1$ Jessup M, Brozena S: Heart failure. N Engl J Med 2003;348:2007-2018.

2 Swynghedauw B: Molecular mechanisms of myocardial remodeling. Physiol Rev 1999;79: 215-262.

3 Koitabashi N, Arai M, Kogure S, Niwano K, Watanabe A, Aoki Y, Maeno T, Nishida T, Kubota S, Takigawa M, Kurabayashi M: Increased connective tissue growth factor relative to brain natriuretic peptide as a determinant of myocardial fibrosis. Hypertension 2007;49:1120-1127.

4 Tsoutsman T, Wang X, Garchow K, Riser B, Twigg S, Semsarian C: CCN2 plays a key role in extracellular matrix gene expression in severe hypertrophic cardiomyopathy and heart failure. J Mol Cell Cardiol 2013;62:164-178.

$\checkmark 5$ Chen MM, Lam A, Abraham JA, Schreiner GF, Joly AH: CTGF expression is induced by TGF-beta in cardiac fibroblasts and cardiac myocytes: a potential role in heart fibrosis. J Mol Cell Cardiol 2000;32:1805-1819.

6 Finckenberg P, Inkinen K, Ahonen J, Merasto $S$, Louhelainen M, Vapaatalo $H$, Muller D, Ganten D, Luft F, Mervaala E: Angiotensin II

Downregulation of MicroRNA-19b and Ang II-Induced CTGF Expression induces connective tissue growth factor gene expression via calcineurin-dependent pathways. Am J Pathol 2003;163:355-366.

7 Perbal B: CCN proteins: multifunctional signalling regulators. Lancet 2004;363:62-64.

$>8$ Bork P: The modular architecture of a new family of growth regulators related to connective tissue growth factor. FEBS Lett 1993;327: 125-130.

-9 Blom IE, Goldschmeding R, Leask A: Gene regulation of connective tissue growth factor: new targets for antifibrotic therapy? Matrix Biol 2002;21:473-482.

10 Ahmed MS, Øie E, Vinge LE, Yndestad A, Øystein Andersen G, Andersson Y, Attramadal T, Attramadal $\mathrm{H}$ : Connective tissue growth factor - a novel mediator of angiotensin II-stimulated cardiac fibroblast activation in heart failure in rats. J Mol Cell Cardiol 2004;36:393-404.

11 Sopel MJ, Rosin NL, Falkenham AG, Bezuhly M, Esmon CT, Lee TD, Liwski RS, Légaré JF: Treatment with activated protein $\mathrm{C}(\mathrm{aPC})$ is protective during the development of myocardial fibrosis: an angiotensin II infusion model in mice. PLoS One 2012; 7:e45663.
12 Matsui Y, Sadoshima J: Rapid upregulation of CTGF in cardiac myocytes by hypertrophic stimuli: implication for cardiac fibrosis and hypertrophy. J Mol Cell Cardiol 2004;37:477481.

13 He Z, Way KJ, Arikawa E, Chou E, Opland DM, Clermont A, Isshiki K, Ma RC, Scott JA, Schoen FJ, Feener EP, King GL: Differential regulation of angiotensin II-induced expression of connective tissue growth factor by protein kinase $\mathrm{C}$ isoforms in the myocardium. J Biol Chem 2005;280:15719-15726.

14 Ambros V: microRNAs: tiny regulators with great potential. Cell 2001;107:823-826.

15 Ikeda S, Kong SW, Lu J, Bisping E, Zhang H, Allen PD, Golub TR, Pieske B, Pu WT: Altered microRNA expression in human heart disease. Physiol Genomics 2007;31:367-373.

16 van Almen GC, Verhesen W, van Leeuwen RE, van de Vrie M, Eurlings C, Schellings MW, Swinnen M, Cleutjens JP, van Zandvoort MA, Heymans S, Schroen B: MicroRNA-18 and microRNA-19 regulate CTGF and TSP-1 expression in age-related heart failure. Aging Cell 2011;10:769-779. 
$\checkmark 17$ Chou E, Suzuma I, Way KJ, Opland D, Clermont AC, Naruse K, Suzuma K, Bowling NL, Vlahos CJ, Aiello LP, King GL: Decreased cardiac expression of vascular endothelial growth factor and its receptors in insulin-resistant and diabetic states: a possible explanation for impaired collateral formation in cardiac tissue. Circulation 2002;105:373-379.

18 Wakasaki H, Koya D, Schoen FJ, Jirousek MR, Ways DK, Hoit BD, Walsh RA, King GL: Targeted overexpression of protein kinase $\mathrm{C}$ beta2 isoform in myocardium causes cardiomyopathy. Proc Natl Acad Sci USA 1997;94: 9320-9325.

19 Kim S, Iwao H: Molecular and cellular mechanisms of angiotensin II-mediated cardiovascular and renal diseases. Pharmacol Rev 2000; 52:11-34.

20 Billet S, Aguilar F, Baudry C, Clauser E: Role of angiotensin II AT1 receptor activation in cardiovascular diseases. Kidney Int 2008;74: 1379-1384.

21 Wei LH, Huang XR, Zhang Y, Li YQ, Chen HY, Yan BP, Yu CM, Lan HY: Smad7 inhibits angiotensin II-induced hypertensive cardiac remodeling. Cardiovasc Res 2013;99:665-673.

22 Li HL, She ZG, Li TB, Wang AB, Yang Q, Wei YS, Wang YG, Liu DP: Overexpression of myofibrillogenesis regulator-1 aggravates cardiac hypertrophy induced by angiotensin II in mice. Hypertension 2007;49:1399-1408.
23 Liu J, Yang F, Yang XP, Jankowski M, Pagano $\mathrm{PJ}$ : NAD $(\mathrm{P}) \mathrm{H}$ oxidase mediates angiotensin II-induced vascular macrophage infiltration and medial hypertrophy. Arterioscler Thromb Vasc Biol 2003;23:776-782.

24 Sopel M, Falkenham A, Oxner A, Ma I, Lee TD, Legare JF: Fibroblast progenitor cells are recruited into the myocardium prior to the development of myocardial fibrosis. Int J Exp Pathol 2012;93:115-124.

25 Moussad EE, Brigstock DR: Connective tissue growth factor: what's in a name? Mol Genet Metab 2000;71:276-292.

26 Shi-Wen X, Leask A, Abraham D: Regulation and function of connective tissue growth factor/CCN2 in tissue repair, scarring and fibrosis. Cytokine Growth Factor Rev 2008;19: 133-144.

27 Touvron M, Escoubet B, Mericskay M, Angelini A, Lamotte L, Santini MP, Rosenthal N, Daegelen D, Tuil D, Decaux JF: Locally expressed IGF1 propeptide improves mouse heart function in induced dilated cardiomyopathy by blocking myocardial fibrosis and SRF-dependent CTGF induction. Dis Model Mech 2012;5:481-491.

28 Frangogiannis NG, Ren G, Dewald O, Zymek P, Haudek S, Koerting A, Winkelmann K, Michael LH, Lawler J, Entman ML: Critical role of endogenous thrombospondin-1 in preventing expansion of healing myocardial infarcts. Circulation 2005; 111 : 2935-2942.
29 Lewis BP, Shih IH, Jones-Rhoades MW, Bartel DP, Burge CB: Prediction of mammalian microRNA targets. Cell 2003;115:787-798.

30 Brennecke J, Stark A, Russell RB, Cohen SM: Principles of microRNA-target recognition. PLoS Biol 2005;3:e85.

31 Jackson RJ, Standart N: How do microRNAs regulate gene expression? Sci STKE 2007; 2007:re1.

32 Nilsen TW: Mechanisms of microRNA-mediated gene regulation in animal cells. Trends Genet 2007;23:243-249.

33 He L, Thomson JM, Hemann MT, HernandoMonge E, Mu D, Goodson S, Powers S, Cordon-Cardo C, Lowe SW, Hannon GJ, Hammond SM: A microRNA polycistron as a potential human oncogene. Nature 2005;435: 828-833.

34 Lakner AM, Steuerwald NM, Walling TL, Ghosh S, Li T, McKillop IH, Russo MW, Bonkovsky HL, Schrum LW: Inhibitory effects of microRNA $19 \mathrm{~b}$ in hepatic stellate cellmediated fibrogenesis. Hepatology 2012;56: 300-310.

35 Ventura A, Young AG, Winslow MM, Lintault L, Meissner A, Erkeland SJ, Newman J, Bronson RT, Crowley D, Stone JR, Jaenisch R, Sharp PA, Jacks T: Targeted deletion reveals essential and overlapping functions of the miR-17 through 92 family of miRNA clusters. Cell 2008;132:875-886. 